\title{
Competitive Effect in The Growth of Pd-Au-Pd Segmental Nanorods
}

\author{
Li Xu, Kai Wang, Bo Jiang, Wei Chen, Fangyan Liu, Hui Hao, Chao Zou, Yun \\ Yang*, Shaoming Huang*
}

Nanomaterials and Chemistry Key Laboratory, Wenzhou University, Wenzhou, Zhejiang 325027, P. R. China

Email: bachier@163.com; smhuang@wzu.edu.cn

\section{The preparation of $\mathbf{H}_{2} \mathrm{PdCl}_{4}$ solution}

A reported method was used to prepare $\mathrm{H}_{2} \mathrm{PdCl}_{4}$ solutions. Briefly, $44.5 \mathrm{mg}$ $\mathrm{PdCl}_{2}$ was introduced to $25 \mathrm{~mL} \mathrm{HCl}(0.02 \mathrm{M})$ and then the mixture was heated in a 50

${ }^{\circ} \mathrm{C}$ water bath until $\mathrm{PdCl}_{2}$ was dissolved completely. ${ }^{1}$ Finally, 5 min magnetic stirring was needed to obtain a homogenous solution.

\section{The preparation of Au decahedra}

Our previous method was used to prepare Au decahedra with different sizes. ${ }^{2}$ In a typical synthesis, $5 \mathrm{uL} \mathrm{HAuCl}_{4}(0.48 \mathrm{M})$ aqueous solution was added into $10 \mathrm{~mL}$ DEG containing $0.25 \mathrm{~mL}$ PDDA was added. The solution was stirred vigorously for $10 \mathrm{~min}$ and a yellow solution formed. $3 \mathrm{~mL}$ DEG solution containing $6 \mathrm{mg} \mathrm{AgNO}_{3}$ was then introduced to above yellow solution and the mixture was stirred for another 3 min. The resulting solution was heated in a given-temperature oil bath. $\mathrm{Au}$ decahedra size could be adjusted through controlling reaction temperature. After 30 
min, the solution was cooled down to room temperature. Au decahedra with different sizes could be synthesized through controlling reaction temperature.

In order to remove excess DEG, PDDA and other byproduct, $9 \mathrm{~mL}$ water was added to $1 \mathrm{~mL}$ as-prepared colloid and then the products were collected through 20 min centrifuging $(12000 \mathrm{rpm})$. The precipitation was redispersed into $9 \mathrm{~mL}$ water again. Three drops of ammonia (Mass 13\%) were introduced for removing $\mathrm{AgCl}$ (ammonia can form soluble $\left[\mathrm{Ag}\left(\mathrm{NH}_{3}\right)_{2}\right]^{+}$complexe with $\mathrm{AgCl}$ ). Then Au decahedra were collected through centrifuge (12000rpm) again. To remove ammonia and $\left[\mathrm{Ag}\left(\mathrm{NH}_{3}\right)_{2}\right]^{+}$, centrifuging should be done another time. The resulting Au decahedra were dissolved in $1 \mathrm{~mL}$ water and used for preparing Pd-Au-Pd NRs.

\section{The preparation of single-crystalline Au nanorods}

A seeded growth was used to synthesize single-crystalline Au nanorods. ${ }^{3}$ (1) The preparation of 2-5 nm Au seeds. $5 \mathrm{~mL} 0.5 \mathrm{mM} \mathrm{HAuCl}_{4}$ was introduced into $5 \mathrm{~mL}$ of 0.2 M CTAB solution, resulting in the formation of a yellow solution. $0.6 \mathrm{~mL}$ of freshly prepared ice-cold $0.01 \mathrm{M} \mathrm{NaBH}_{4}$ was diluted with $1 \mathrm{~mL}$ ice-cold water and then the solution was immediately introduced to the above $\mathrm{Au}(\mathrm{III})$-CTAB solution under vigorous stirring (1200 rpm). A color from yellow to brown was observed, indicating that $\mathrm{Au}$ nanoparticles formed. After $5 \mathrm{~min}$, the stirring was stopped. In order to make sure that $\mathrm{NaBH}_{4}$ decomposed completely, the seed solution was aged at room temperature for at least $2 \mathrm{~h}$ before use. (2) The synthesis of Au nanorods. $7.0 \mathrm{~g}$ $\mathrm{CTAB}$ and $1.234 \mathrm{~g}$ of sodium oleate were dissolved in $250 \mathrm{~mL} 50{ }^{\circ} \mathrm{C}$ water under ultrasonic, then the solution was cooled down to $30{ }^{\circ} \mathrm{C}$. $18 \mathrm{~mL} \mathrm{AgNO}_{3}$ solution $(4$ 
$\mathrm{mM}$ ) and $250 \mathrm{~mL}$ of $1 \mathrm{mM} \mathrm{HAuCl}{ }_{4}$ solution were added successively under gentle stirring. After $90 \mathrm{~min}$ of stirring $(700 \mathrm{rpm})$, the solution became colorless because $\mathrm{Au}(\mathrm{III})$ was reduced to $\mathrm{Au}(\mathrm{I})$. In order to adjust the growth rate, $3 \mathrm{~mL} \mathrm{HCl}$ (37 wt. \% in water, $12.1 \mathrm{M}$ ) was introduced. After the solution was stirred for another $15 \mathrm{~min}$ (400 rpm), $1.25 \mathrm{~mL}$ of $0.064 \mathrm{M}$ ascorbic acid was added as reducing agent under stirring (1000 rpm). Finally, $0.2 \mathrm{~mL}$ seed solution was injected into above growth solution. The resultant mixture was stirred for $30 \mathrm{~s}$ and left undisturbed at $30^{\circ} \mathrm{C}$ for 12 $\mathrm{h}$ for NR growth. The Au nanorods could be collected by 10 min centrifugation $(7,000$ rpm). Supernatant was discarded and the precipitation was dispersed into $416 \mathrm{~mL}$ water again.

The synthesis of Au@Pd nanocuboids using single-crystalline Au nanorod as seeds

The preparation of $\mathrm{Au} @ \mathrm{Pd}$ nanocuboids was similar to that of $\mathrm{Pd}-\mathrm{Au}-\mathrm{Pd}$ nanorods except for that single-crystalline Au nanorods acted as seeds instead of $\mathrm{Au}$ decahedra.

\section{The synthesis of truncated Au octahedra}

A method was used to synthesize truncated Au octahedra. ${ }^{4}$ Typically, $10 \mathrm{~mL}$ DEG was mixed with $0.2 \mathrm{~mL}$ PDDA under vigorous stirring, and then $25 \mathrm{uL} \mathrm{HAuCl}{ }_{4}$ $(0.48 \mathrm{M})$ aqueous solution was introduced. $0.05 \mathrm{~mL}$ of $\mathrm{AgNO}_{3} \mathrm{DEG}$ solution (2 $\mathrm{mg} / \mathrm{mL}$ ) was injected into above solution. After 3 min stirring (1000 rpm), the resulting solution was heated in $200{ }^{\circ} \mathrm{C}$ oil bath without disturbance. The solution gradually became red, indicating that $\mathrm{Au}$ nanoparticles formed. After $30 \mathrm{~min}$, the 
solution was allowed to cool down to room temperature. For purification, $180 \mathrm{~mL}$ water was added to colloid and then products were collected with $12000 \mathrm{rpm}$ centrifuge for $20 \mathrm{~min}$. The product was dispersed in $100 \mathrm{~mL}$ water and precipitated through centrifuge again. The washing procedure was repeated for three times and the resulting Au nanoparticles were dissolved in $20 \mathrm{~mL}$ water.

\section{The synthesis of Au@Pd nanocubes using truncated Au octahedra as seeds}

The preparation of $\mathrm{Au} @ \mathrm{Pd}$ nanocubes was similar to that of $\mathrm{Pd}-\mathrm{Au}-\mathrm{Pd}$ nanorods except for that truncated $\mathrm{Au}$ octahedra acted as seeds instead of $\mathrm{Au}$ decahedra.

\section{Electrochemical measurement}

Before each experiment, the GC electrode was polished with the slurry of alumina NPs to a mirror. For catalyst preparation, $5 \mathrm{mg} \mathrm{Pd}-\mathrm{Au}-\mathrm{Pd} \mathrm{NRs}(5 \mathrm{mg})$ and an equal amount of carbon black (Vulcan XC-72) were mixed in $10 \mathrm{~mL}$ water, and then the mixture was sonicated for $2 \mathrm{~h}$. The black carbon supporting Pd-Au-Pd NRs was precipitated through centrifugation $(5000 \mathrm{rpm})$ and washed with ethanol three times. The purified $\mathrm{Pd}-\mathrm{Au}-\mathrm{Pd} / \mathrm{C}$ catalyst was dispersed in $5 \mathrm{~mL}$ water. This mixture was sonicated for $1 \mathrm{~h}$ to ensure uniform distribution. The content of metal in catalyst was

measured using inductively coupled plasma mass spectrometry (ICP-MS). $20 \mu \mathrm{L}$ of prepared catalyst was casted onto electrode with $3 \mathrm{~mm}$ glassy carbon and then $10 \mathrm{uL}$ $01 \%$ nifion solution was casted for fixing catalyst. The electrode was dried for $1 \mathrm{~h}$ under infrared light and acted as working electrode.

A CHI 760 electrchemical workstation (CH Instruments Inc. Austin) was used in all electrochemical measurements. Before electrochemical oxidization of formic acid, 
A CO-stripping technology was used to remove impurity and activate surface atoms. ${ }^{5}$ A solution containing $0.1 \mathrm{M} \mathrm{KClO}_{4}$ and $1 \mathrm{mM} \mathrm{NaOH}$ acted as electrolyte. $\mathrm{CO}$ was introduced and bubbled for $30 \mathrm{~min}$ for making sure that $\mathrm{O}_{2}$ was removed completely. Then the electrode served as working electrode and an electrochemical potential cycling was carried out $(-1.2$ to $+0.6 \mathrm{~V}$ vs $\mathrm{Ag} / \mathrm{AgCl}$ for 50 cycles at a scan rate of 0.05 $\left.\mathrm{V} \mathrm{s}^{-1}\right)$.

After CO-stripping, the activated electrode further acted as working electrode for electrochemical oxidization of formic acid in $0.5 \mathrm{M} \mathrm{H}_{2} \mathrm{SO}_{4}$ and $0.5 \mathrm{M}$ formic acid. A Pt flake of $1 \mathrm{~cm}^{2}$ area and an $\mathrm{Ag} / \mathrm{AgCl}-\mathrm{KCl}$ (saturated) electrode were used as the counter electrode and the reference electrode respectively. The cyclic voltammograms (CV) of methanol oxidation were measured at the scan rate of $100 \mathrm{mV} / \mathrm{s}$ in the potential range of $-0.8 \mathrm{~V}$ to $0.4 \mathrm{~V}$ at room temperature. An similar electrochemical method was used to calculate the active surface area (The electrolyte was $0.1 \mathrm{M}$ $\mathrm{HClO}_{4}$, scanning rate was $100 \mathrm{mV} / \mathrm{S}$ and the potential ranged from $-0.3 \mathrm{~V}$ to $\left.1.2 \mathrm{~V}\right){ }^{5}$

\section{References}

1. Yang, Y.; Wang, W.; Li, X.; Chen, W.; Fan, N.; Zou, C.; Chen, X.; Xu, X.; Zhang, L.; Huang, S. Controlled growth of $\mathrm{Ag} / \mathrm{Au}$ bimetallic nanorods through kinetics control. Chem. Mater. 2013, 25, 34-41.

2. Wang, F.; Sun, L.-D.; Feng, W.; Chen, H. J.; Yeung, M. H.; Wang, J. F.; Yan, C.H. Heteroepitaxial growth of core-shell and core-multishell nanocrystals composed of palladium and gold. Small 2010, 6, 2566-2575.

3. Ye, X.; Zheng, C.; Chen, J.; Gao, Y.; Murray, C. B. Using Binary Surfactant Mixtures to Simultaneously Improve the Dimensional Tunability and Monodispersity in the Seeded Growth of Gold Nanorods. Nano Lett. 2013, 13, 765-771.

4. Li, X.; Yang, Y.; Zhou, G.; Han, S.; Wang, W.; Zhang, L.; Chen, W.; Zou, C.; Huang, S. The unusual effect of $\mathrm{AgNO}_{3}$ on the growth of $\mathrm{Au}$ nanostructures and their 
catalytic performance. Nanoscale 2013, 5,4976-4985.

5. Tang, Y.; Edelmann, R. E.; Zou, S. Length tunable penta-twinned palladium nanorods: seedless synthesis and electrooxidation of formic acid. Nanoscale 2014, 6, 5630-5633.

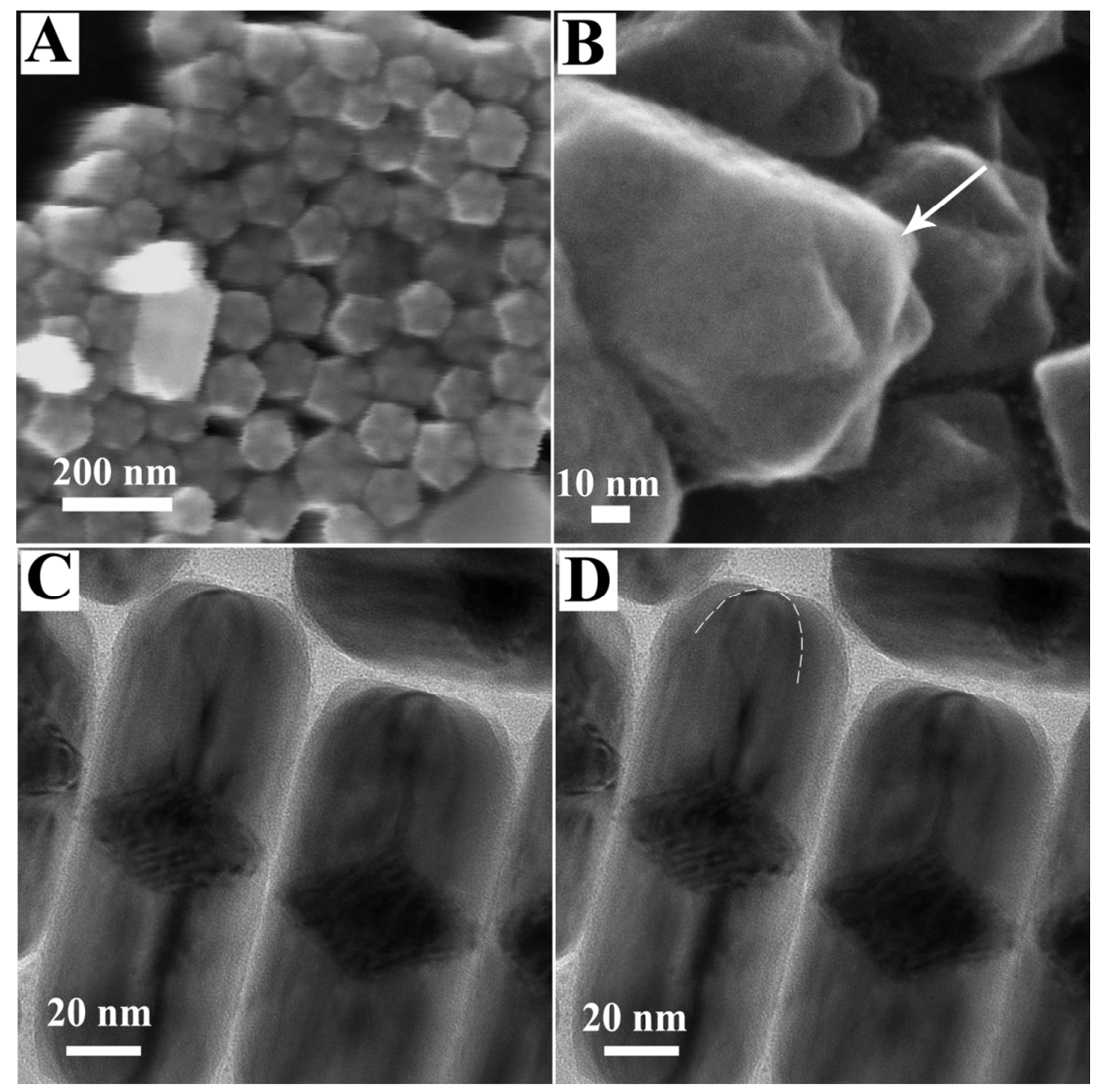

Figure S1. Typical SEM and TEM images of Pd-Au-Pd nanorods (The line in Figure R D marks the view of one (111)). 


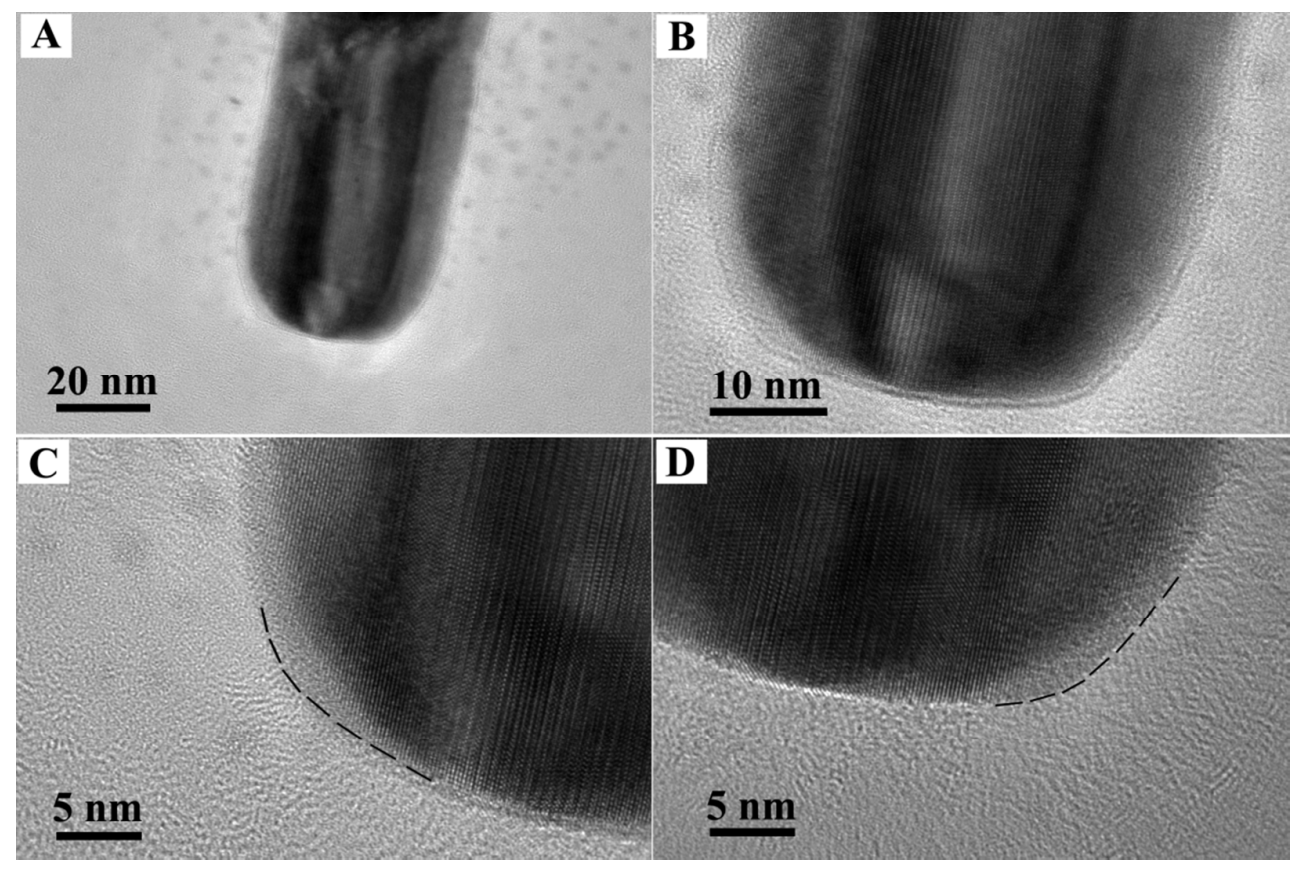

Figure S2. Typical HRTEM images of Pd-Au-Pd nanorods.

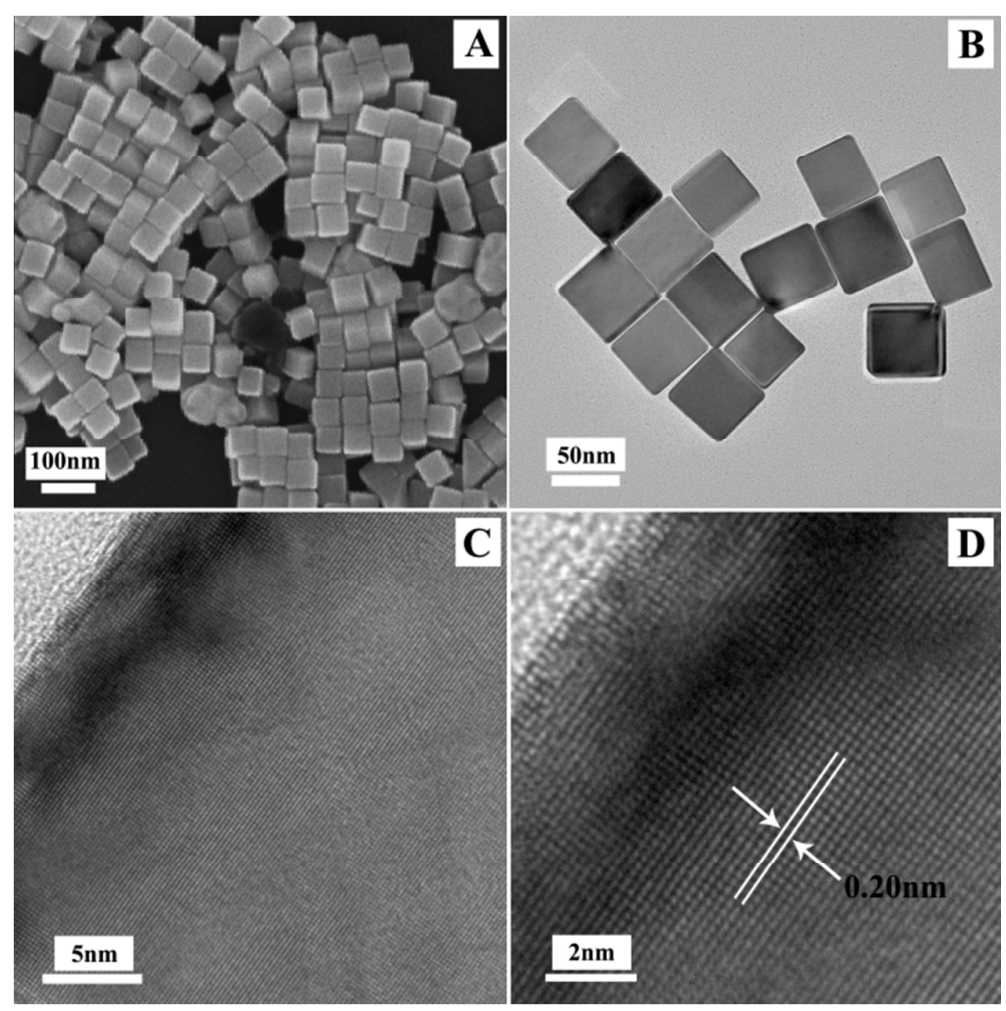

Figure S3. SEM, TEM, HRTEM images of Pd nanocubes prepared using a standard procedure except for that no Au decahedra were added. 


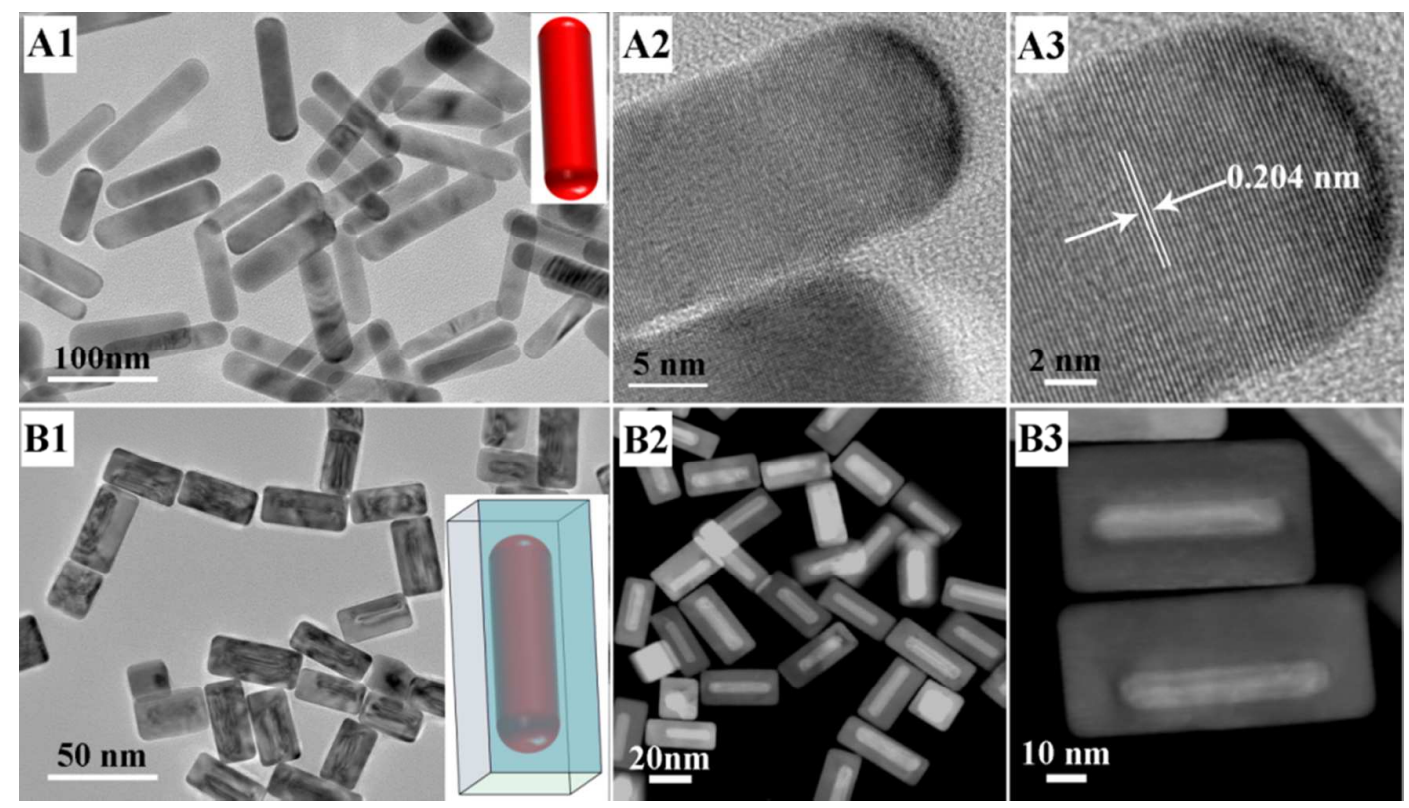

Figure S4. TEM, HRTEM and HAADF images of (A1-A3) single-crystalline Au nanorods and (B1-B3) Au@Pd nanocuboids prepared through overgrowing Pd on Au nanorods.

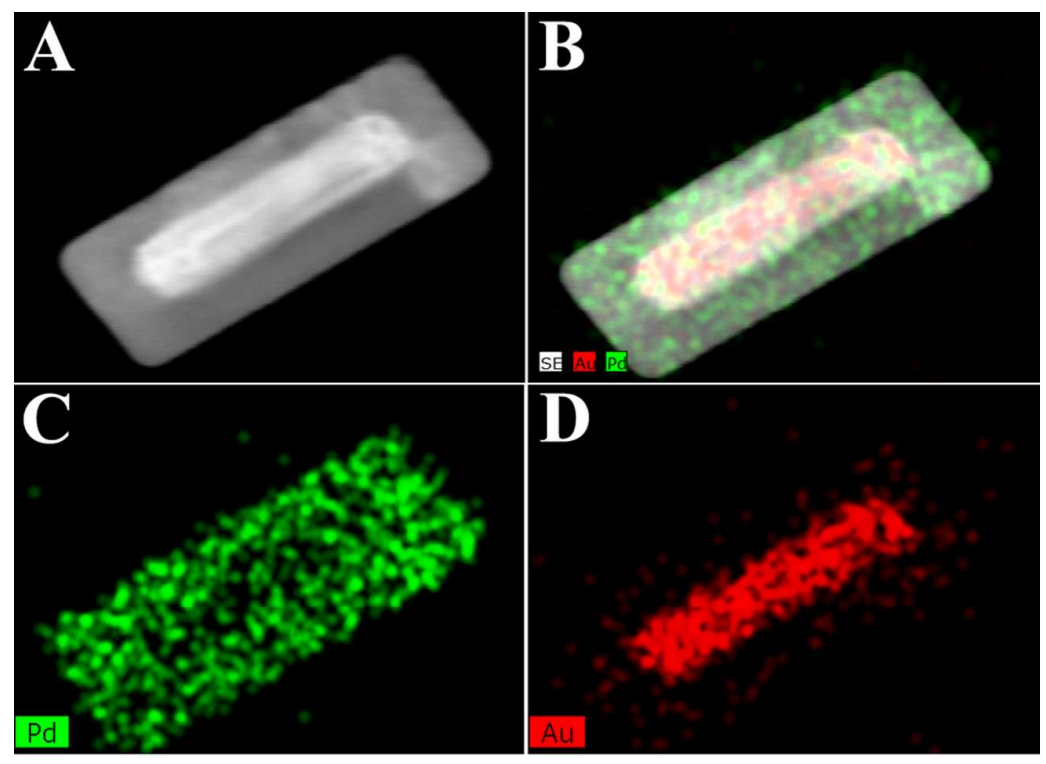

Figure S5. HAADF and elemental mapping results of one Au@Pd nanocuboid shown in Figure S4B: (A) HAADF image; (B) Pd and Au; (C) Pd; (D) Au. 

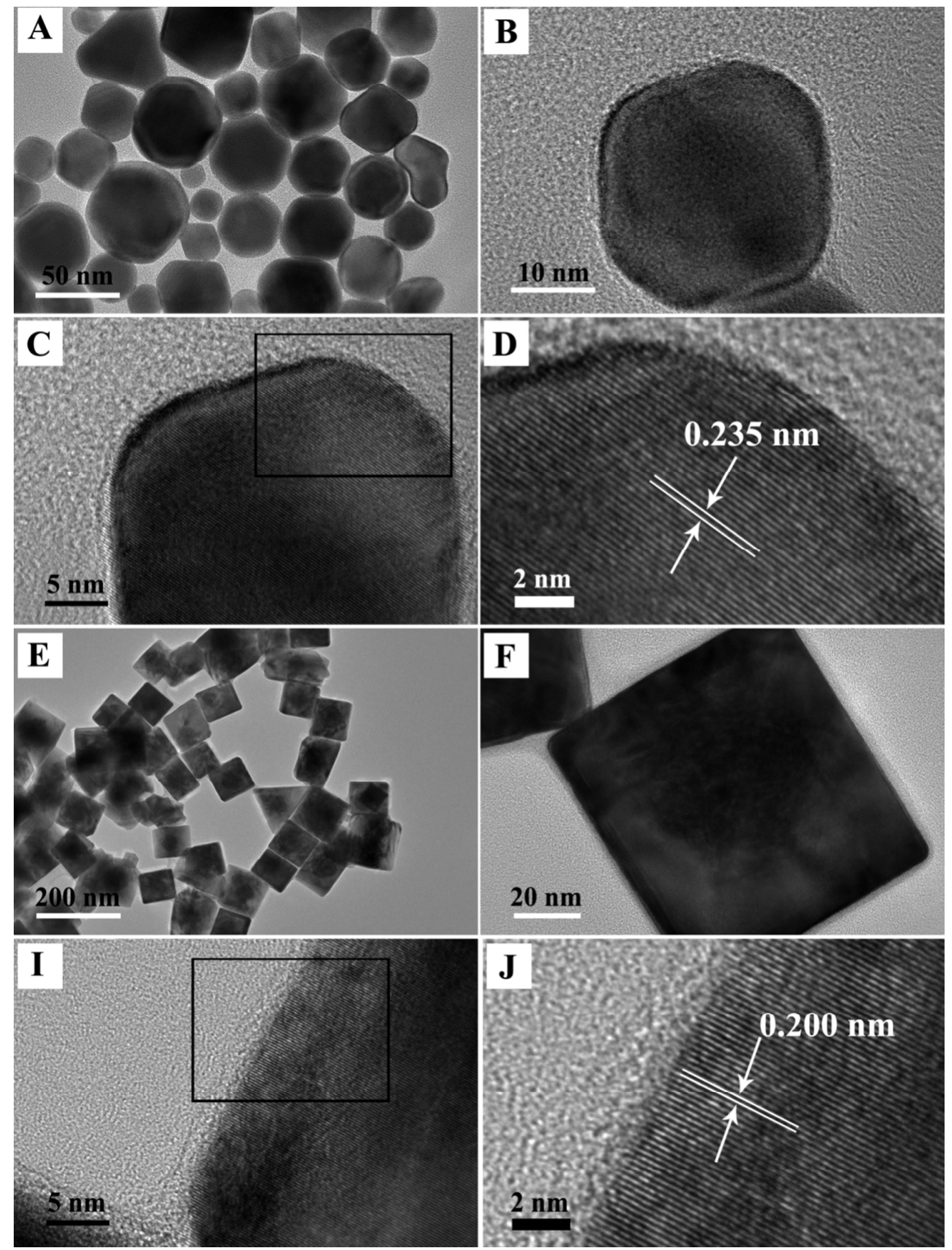

Figure S6. TEM and HRTEM images of (A-D) Au truncated octahedral seeds and (B-

J) corresponding $\mathrm{Au} @ \mathrm{Pd}$ nanocubes prepared through overgrowing Pd (Figure S6D and Figure S6J are the enlarged images of selected areas marked by the black box in

Figure S6C and Figure S6I respectively) 

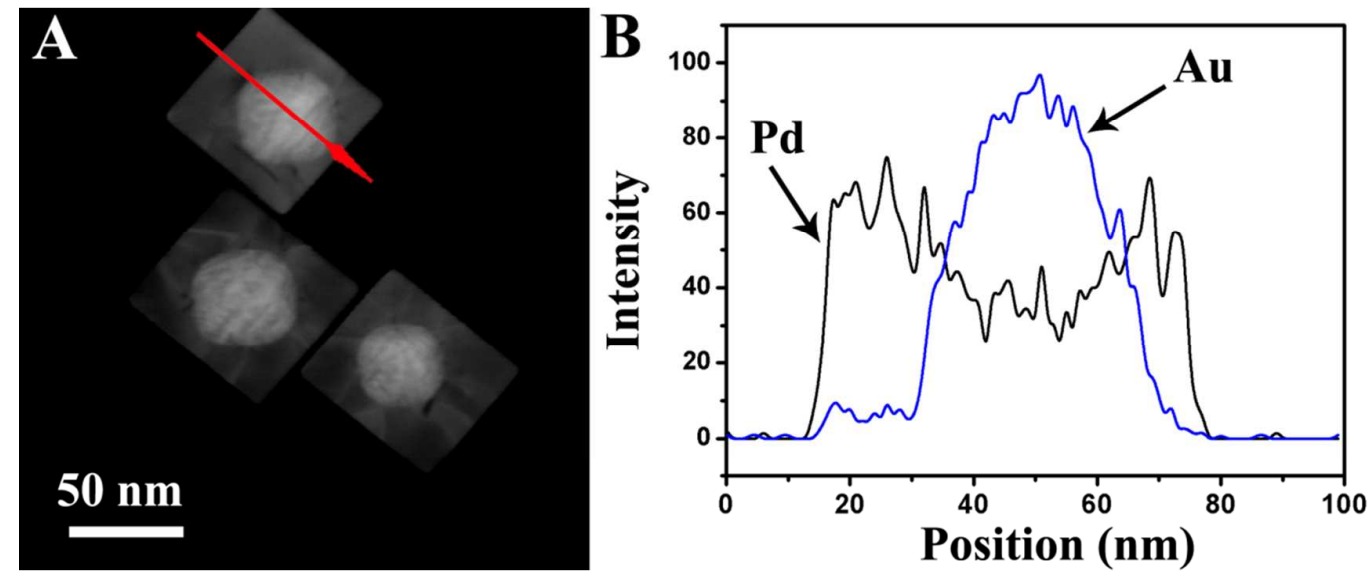

Figure S7. (A) HAADF image of Au@Pd nanoparticles shown in Figure S6E and (B) elemental line profile of one nanoparticle (The red arrow in Figure S7A represents the scanning direction).
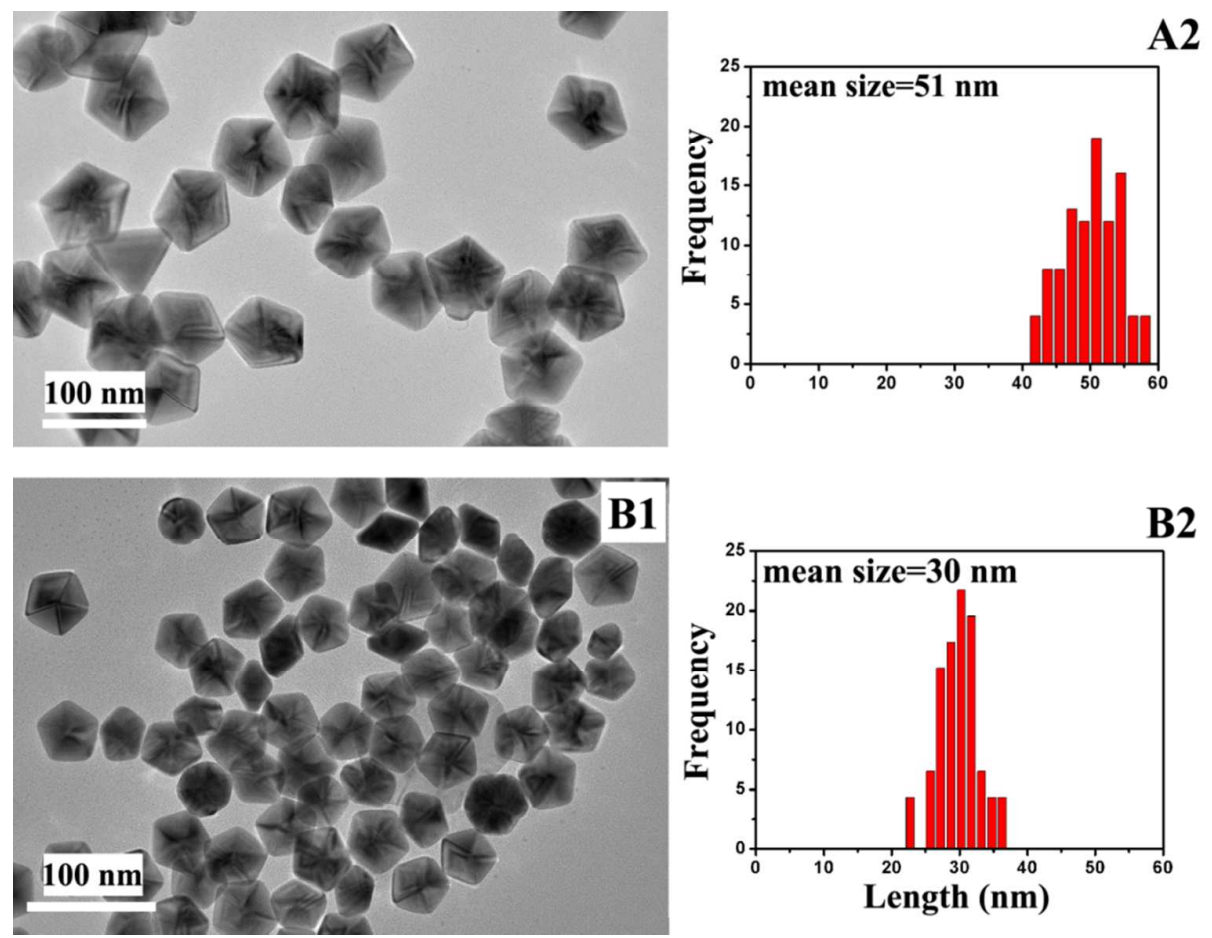

Figure S8. TEM images of Au decahedral seeds with different sizes and corresponding histograms of size: (A1-A2) $51 \mathrm{~nm}$; (B1-B2) $30 \mathrm{~nm}$. 

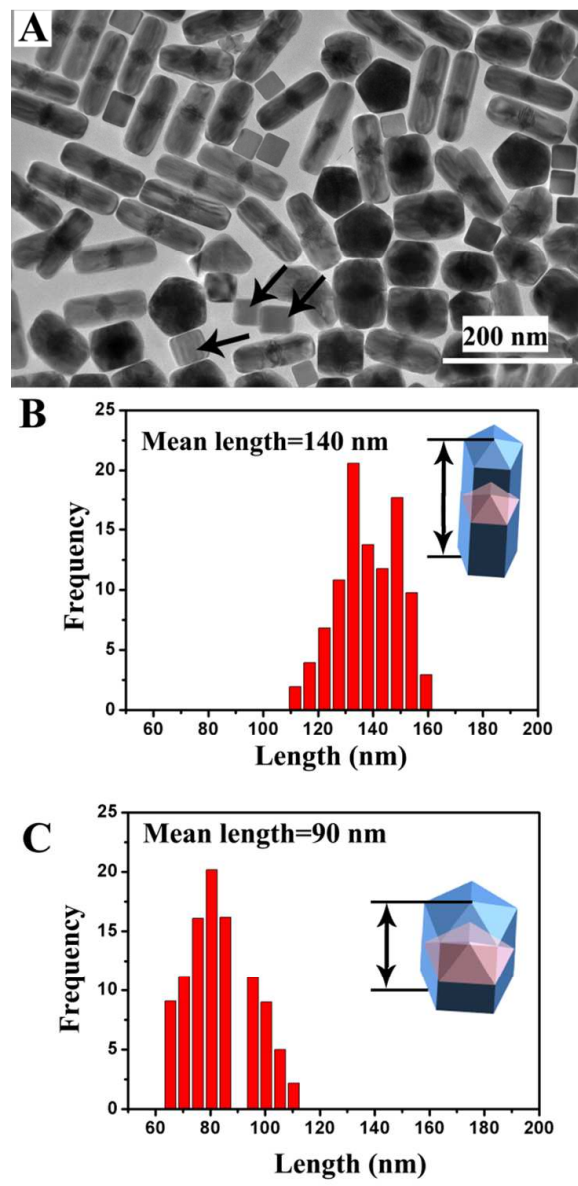

Figure S9. (A) TEM image of products prepared using mixed $\mathrm{Au}$ decahedral seeds $(50 \mathrm{~nm}$ and $30 \mathrm{~nm})$ (The mass ratio of large decahedra and small decahedra was 1). (B) Histogram of longitudinal length of $\mathrm{Pd}-\mathrm{Au}-\mathrm{Pd}$ nanorod from $30 \mathrm{~nm}$ seeds; (C) Histogram of of longitudinal length of Pd-Au-Pd nanorods from $51 \mathrm{~nm}$ seeds.

Discussion about Figure S8 and S9. When the mixed seeds (30 nm and $51 \mathrm{~nm} \mathrm{Au}$ decahedral nanoparticles) were used, the length of Pd-Au-Pd nanorods is not uniform. The nanorods from the overgrowth on large sized Au decahedra are shorter than those on small Au decahedra (Figure S9B and S9C). This indicates that the growth rate on large Au decahedral seeds was slower than that on small decahedral seeds due to size effect (Huang, S. et al., Chem. Mater. 2013, 25, 34-41.). Therefore, in case of large sized Au decahedral seeds, their low activity reduces the tendency that Pd deposits on $\mathrm{Au}$ decahedra, and relatively facilitates self-nucleation. Therefore, when large sized $\mathrm{Au}$ decahedra acted as seeds, the self-nucleation was not caused only by the low 
number of active sites. Their low activity due to size effect also made contribution to this.

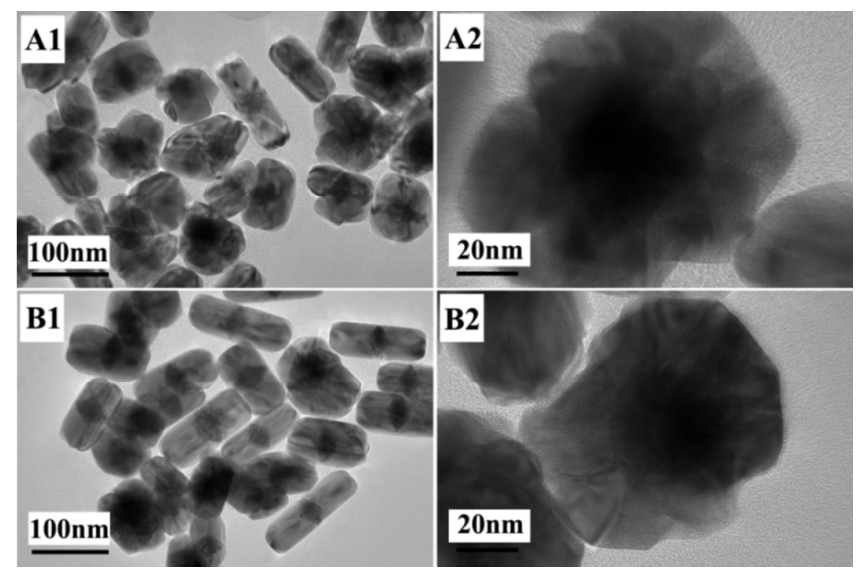

Figure S10. TEM and HRTEM images of products prepared at different temperatures in a standard procedure $\left(\mathrm{H}_{2} \mathrm{PdCl}_{4} / \mathrm{Au}=8 ; \mathrm{KI} / \mathrm{H}_{2} \mathrm{PdCl}_{4}=4 ; \mathrm{AA} / \mathrm{H}_{2} \mathrm{PdCl}_{4}=2\right)$ : $(\mathrm{A} 1-\mathrm{A} 2) 50$ ${ }^{\circ} \mathrm{C}$; (B1-B2) $70{ }^{\circ} \mathrm{C}$.

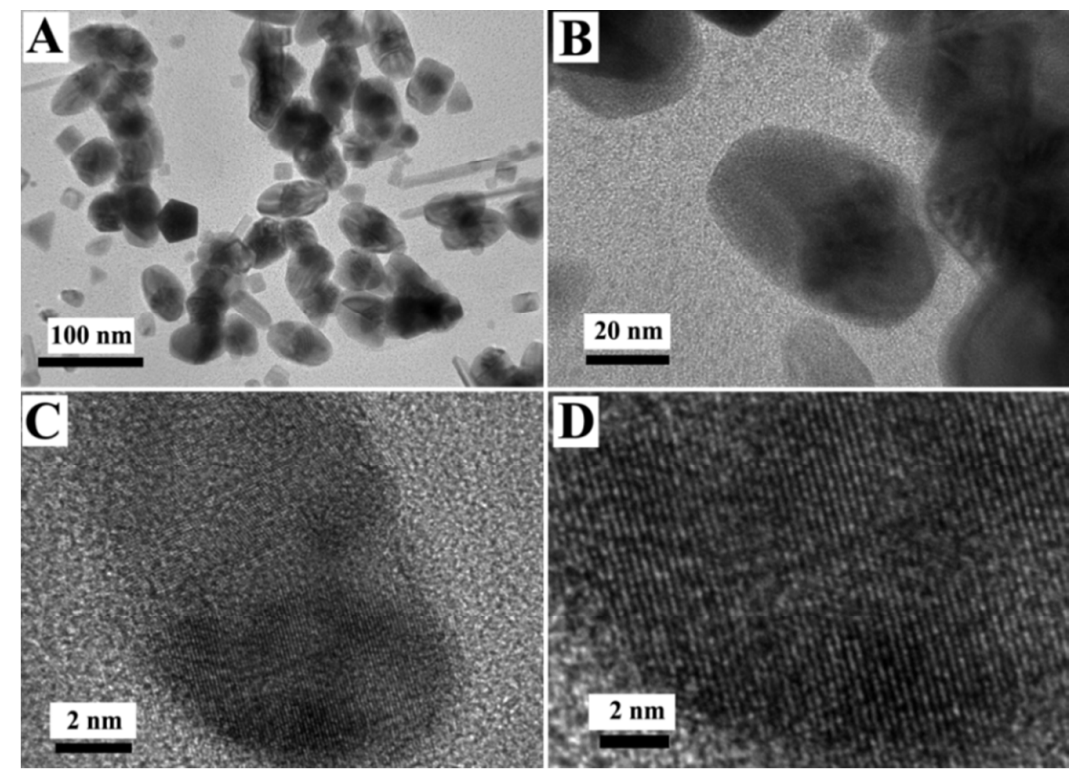

Figure S11. TEM and HRTEM images of product prepared using a standard procedure at $140{ }^{\circ} \mathrm{C}$ 


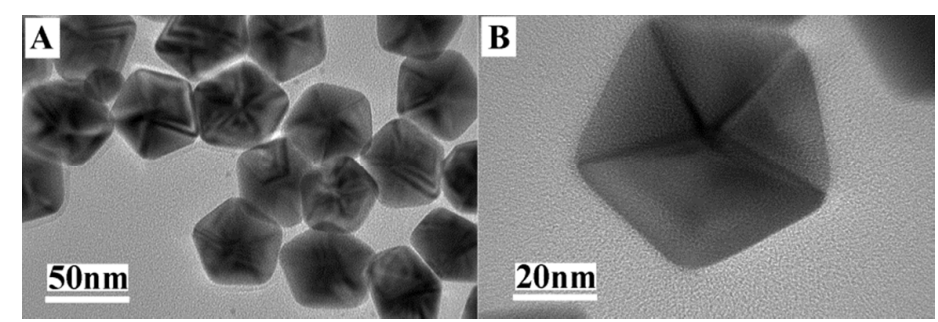

Figure S12. TEM and HRTEM images of product prepared in a standard procedure (Reaction time was $3 \mathrm{~h} ; \mathrm{H}_{2} \mathrm{PdCl}_{4} / \mathrm{Au}=5 ; \mathrm{AA} / \mathrm{H}_{2} \mathrm{PdCl}_{4}=2 ; \mathrm{KI} / \mathrm{H}_{2} \mathrm{PdCl}_{4}=6$ ). This result shows that no growth of $\mathrm{Pd}$ on $\mathrm{Au}$ decahedra occurred.

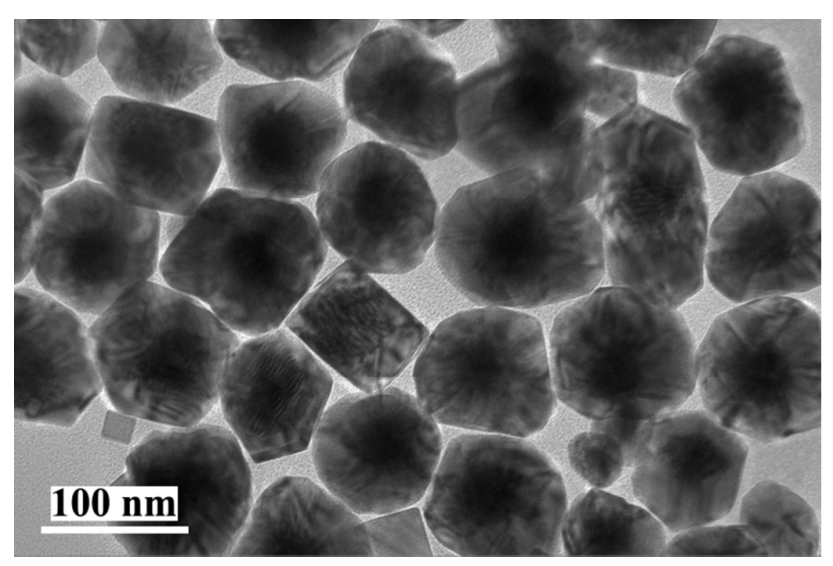

Figure S13. TEM images of products prepared in a standard procedure $\left(\mathrm{H}_{2} \mathrm{PdCl}_{4} / \mathrm{Au}\right.$

$$
=5 ; \mathrm{AA} / \mathrm{H}_{2} \mathrm{PdCl}_{4}=2 ; \mathrm{KI} / \mathrm{H}_{2} \mathrm{PdCl}_{4}=0.05 \text { ) }
$$
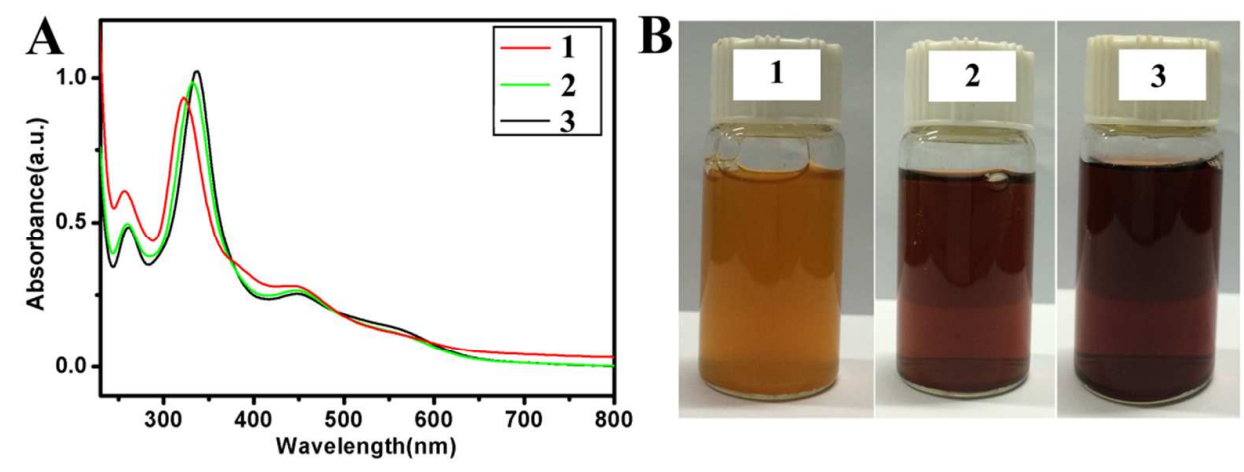

Figure S14. (A) UV-vis spectra and (B) optical photographs of solution containing different concentration of $\mathrm{KI}$ : (1) $0.1 \mathrm{mM}$; (2) $0.3 \mathrm{mM}$; (3) $0.6 \mathrm{mM}$; (CTAB concentration was $0.1 \mathrm{M}$ and $\mathrm{H}_{2} \mathrm{PdCl}_{4}$ was $0.1 \mathrm{mM}$ in three cases). 

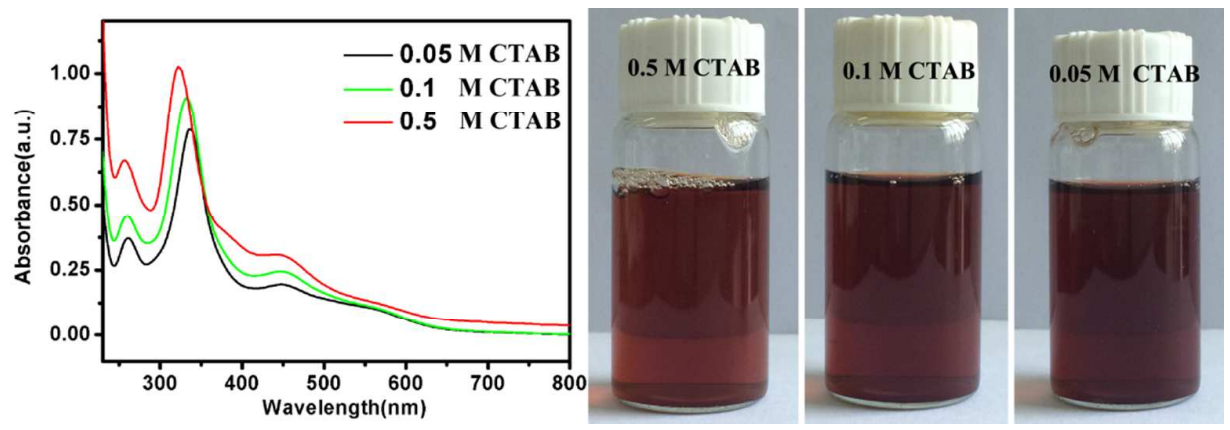

Figure S15. (A) UV-vis spectra and (B) optical photographs of solution containing different concentration of CTAB (KI was $0.3 \mathrm{mM}$ and $\mathrm{H}_{2} \mathrm{PdCl}_{4}$ was $0.1 \mathrm{mM}$ in three cases).

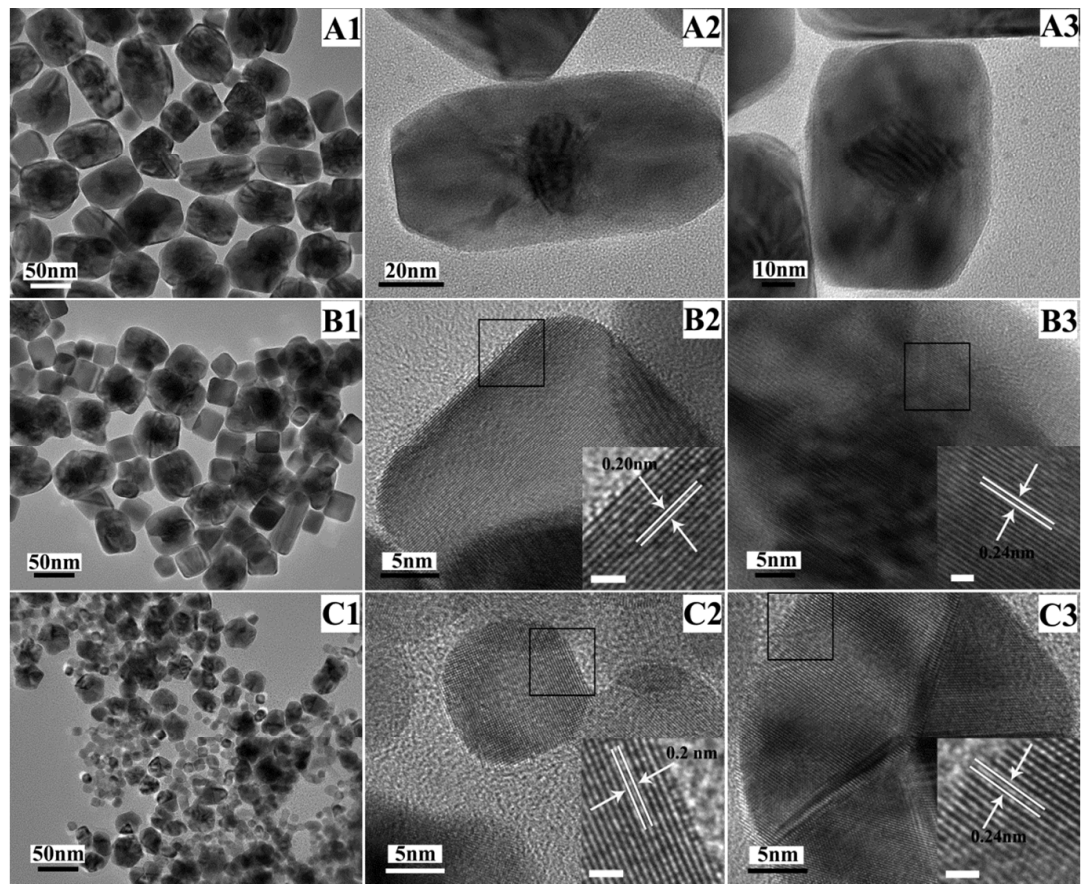

Figure S16. TEM images of products prepared using different concentrations of CTAC: (A1-A2) 2 M; (B1-B2) 1 M; (C1-C2) 0.5 M. Insets in Figure S16B2, 8B3, 8C2, 8C3 are the enlarged images of areas marked by the boxes. Compared with CTAB, CTAC is unable to effectively protect $\mathrm{Au}$ decahedra against being inactivated by KI. The growth of Pd on Au decahedra was blocked and subsequently pure Pd NPs formed. 

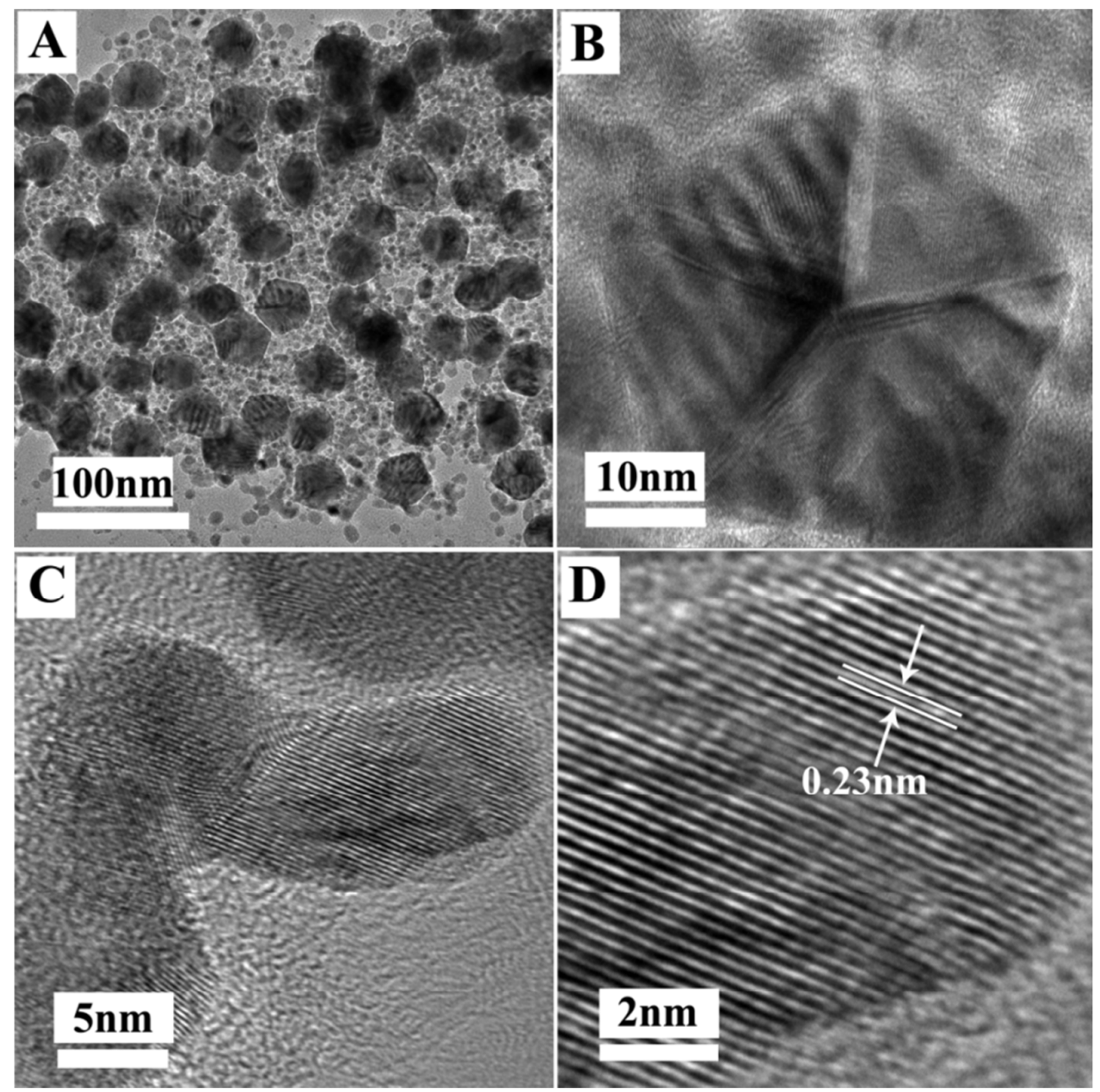

Figure S17. TEM and HRTEM images of products prepared using PVP as capping agent. This result show that the Au decahedra was completely inactivated by KI when no halide ions was present. For this reason, almost no any growth of $\mathrm{Pd}$ on $\mathrm{Au}$ decahedra surface happened. 


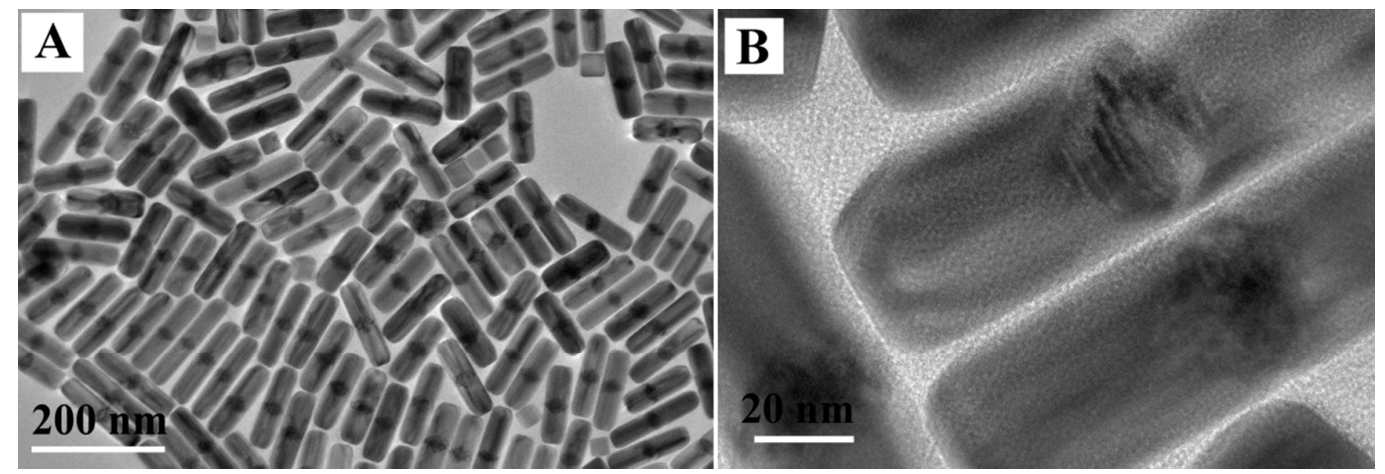

Figure S18. TEM images of products prepared in a standard procedure.

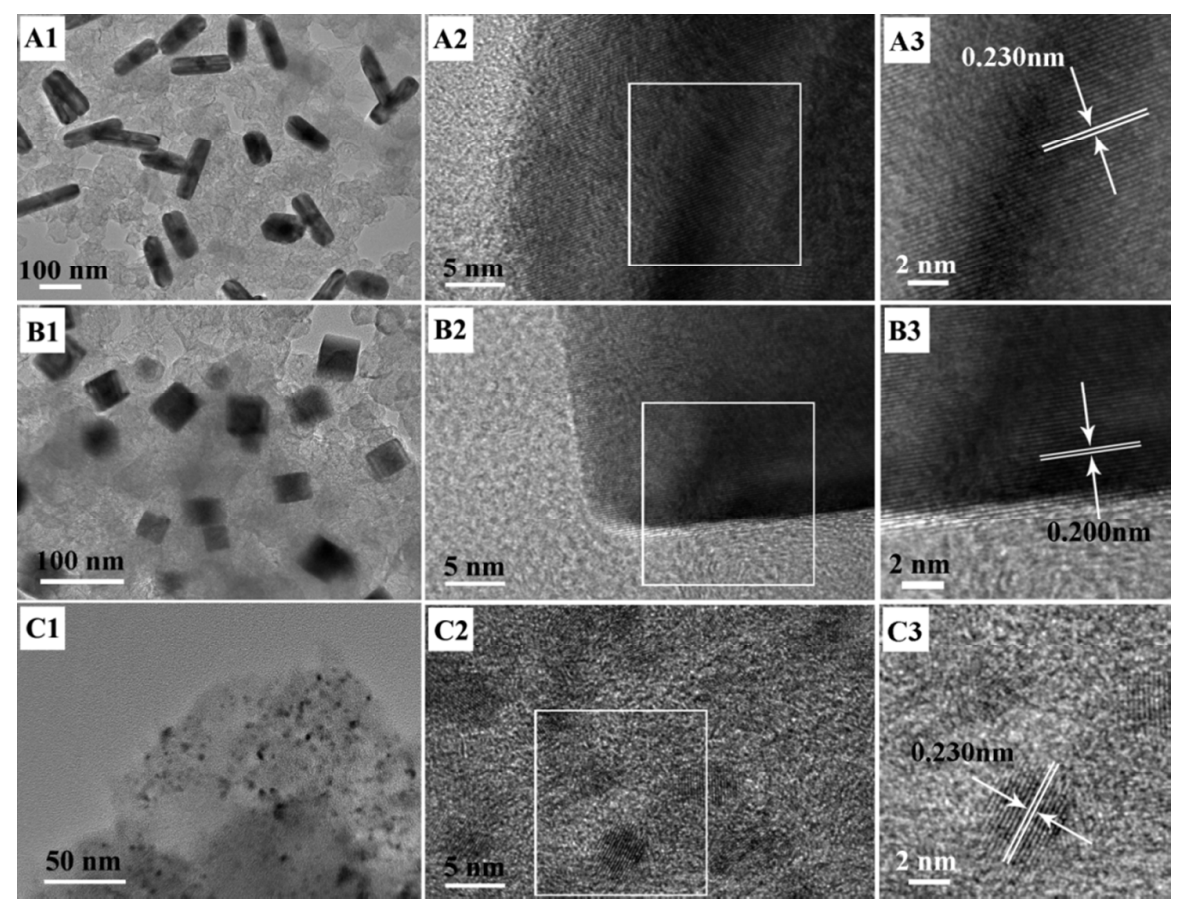

Figure S19. TEM and HRTEM images of various catalysts: (A1-A3) carbonsupported Pd-Au-Pd penta-fold twinned NRs; (B1-B3) carbon-supported Pd nanocubes; (A1-A3) commercial Pd/C. Figure S19A3, S19B3 and S19C3 are the enlarged images of positions marked by the box in Figure S19A2, S19B2 and S19C2 respectively. 